\title{
The oxygen reserve index (ORI): a new tool to monitor oxygen therapy
}

\author{
T. W. L. Scheeren ${ }^{1}$ F. J. Belda ${ }^{2}$ A. Perel ${ }^{3}$
}

Received: 8 May 2017 / Accepted: 17 July 2017 / Published online: 8 August 2017

(C) The Author(s) 2017. This article is an open access publication

\begin{abstract}
Supplemental oxygen is administered in the vast majority of patients in the perioperative setting and in the intensive care unit to prevent the potentially deleterious effects of hypoxia. On the other hand, the administration of high concentrations of oxygen may induce hyperoxia that may also be associated with significant complications. Oxygen therapy should therefore be precisely titrated and accurately monitored. Although pulse oximetry has become an indispensable monitoring technology to detect hypoxemia, its value in assessing the oxygenation status beyond the range of maximal arterial oxygen saturation $\left(\mathrm{SpO}_{2} \geq 97 \%\right)$ is very limited. In this hyperoxic range, we need to rely on blood gas analysis, which is intermittent, invasive and sometimes delayed. The oxygen reserve index (ORI) is a new continuous non-invasive variable that is provided by the new generation of pulse oximeters that use multi-wavelength pulse co-oximetry. The ORI is a dimensionless index that reflects oxygenation in the moderate hyperoxic range $\left(\mathrm{PaO}_{2}\right.$ $100-200 \mathrm{mmHg}$ ). The ORI may provide an early alarm when oxygenation deteriorates well before any changes in $\mathrm{SpO}_{2}$ occur, may reflect the response to oxygen administration (e.g., pre-oxygenation), and may facilitate oxygen titration and prevent unintended hyperoxia. In this review we describe this new variable, summarize available data
\end{abstract}

T. W. L. Scheeren

t.w.1.scheeren@umcg.nl

1 Department of Anaesthesiology, University of Groningen, University Medical Center Groningen, PO Box 30 001, 9700 RB Groningen, The Netherlands

2 Department of Anesthesiology, Hospital Clínico Universitario, Valencia, Spain

3 Department of Anesthesiology and Intensive Care, Sheba Medical Center, Tel Aviv University, Tel Aviv, Israel and preliminary experience, and discuss its potential clinical utilities in the perioperative and intensive care settings.

Keywords Monitoring · Oxygenation · Pulse oximetry · Hypoxia $\cdot$ Hyperoxia $\cdot$ Oxygen therapy $\cdot$ Critical care $\cdot$ Perioperative period - Operating rooms - Preoxygenation · Hypoxemia $\cdot$ Hyperoxemia $\cdot$ Hyperoxic acute lung injury

\section{Background}

Oxygen administration can be life-saving since lack of oxygen (hypoxia) is deleterious and should be prevented or treated in a timely manner. This is why the vast majority of patients in the operating room and in the intensive care unit (ICU) receive supplementary oxygen. However, oxygen has to be considered as a drug since the administration of too much oxygen and the presence of hyperoxia are known to be associated with significant complications [1]. Oxygen therapy should therefore be precisely titrated and accurately monitored to avoid the consequences of both hypoxia and hyperoxia [2]. Pulse oximetry has become the prevalent monitoring technology to detect the presence of hypoxemia [3]. However, in order to monitor the oxygenation status when the arterial blood is nearly fully saturated $\left(\mathrm{SpO}_{2} \geq 97 \%\right)$ we need to rely on blood gas analysis, which is intermittent and invasive and occasionally delayed. New technological developments in multiwavelength pulse cooximetry expand our abilities to monitor oxygenation in the moderate hyperoxic range $\left(\mathrm{PaO}_{2} 100-200 \mathrm{mmHg}\right)$. In this review we will describe this new variable, termed the Oxygenation Reserve Index (ORI), and discuss its potential clinical utilities. 


\section{The problem of hypox(em)ia}

Although low oxygen tensions $\left(\mathrm{PaO}_{2}\right.$ values $<75 \mathrm{mmHg}$ or $<10 \mathrm{kPa}$ ) are frequently observed (e.g. at high altitude) and usually well tolerated by healthy individuals, they are deleterious for patients who undergo major surgery or during critical illness. It should also be noted that oxygen tension is considerably lower at the capillary or mitochondrial level than it is in the atmosphere, alveoli or arterial blood (the "oxygen cascade") [4].

In the perioperative setting, both hypoxia (i.e. lack of oxygen at the tissue level) and hypoxemia (i.e. low blood oxygen level) occur commonly and may be considered a serious safety concern. For instance, a recent report analysing 95,407 anaesthesia records from 2 institutions revealed that $6.8 \%$ of patients had a hypoxemic event (defined by oxygen saturation, $\mathrm{SpO}_{2}<90 \%$ ) during the intraoperative period, and that $3.5 \%$ of patients had a severely hypoxemic event $\left(\mathrm{SpO}_{2}<85 \%\right)$ lasting 2 min or longer [5]. The risk factors for the occurrence of such events include obesity [6, 7], difficult airway [8], rapid sequence induction [9], unrecognized esophageal intubation [8], one-lung ventilation [10], and very young age [7, 11]. Hypoxemic events have been found to be even more frequent in the early postoperative period in the post anaesthesia care unit (PACU). In a prospective blinded observational study including 1500 postoperative patients, $37 \%$ had at least one period of hypoxemia $\left(\mathrm{SpO}_{2}<90 \%\right)$ lasting $\geq 1 \mathrm{~h}$, while in $11 \%$ of patients such hypoxemia lasted $\geq 6$ h [12]. Furthermore, $8 \%$ of patients spent $\geq 5 \mathrm{~min} / \mathrm{h}$ with an $\mathrm{SpO}_{2}<85 \%$, and $3 \%$ spent $\geq 30$ min with an $\mathrm{SpO}_{2}<80 \%$ [12]. Another retrospective analysis of 137,757 patients in the PACU revealed that many of the hypoxemic events occurred $\geq 30 \mathrm{~min}$ after PACU admission, i.e. when the anaesthesiologist has already left the patient and returned back to the OR for the next case [13]. Importantly, about $25 \%$ of these hypoxemic episodes lasted $>10$ min after their onset [13]. The first postsurgical day was similarly found to carry the highest risk of adverse respiratory events, most of them being hypoxic episodes [14]. Risk factors for postoperative hypoxemia include residual effects of anaesthetics, opioids or muscle relaxants [15], atelectasis [16], upper abdominal or thoracic surgery [17], smoking, pulmonary diseases, obesity and advanced age [18-20].

In general, a clear association between progressively lower $\mathrm{PaO}_{2}$ and increasing in-hospital mortality has been demonstrated also in ICU patients [21]. For instance, airway problems may occur in the ICU setting as well [22], and lead to particularly adverse outcome [23]. A recent study on 97,844 mechanically ventilated patients across 165 ICUs in the US revealed that mortality was increased in patients extubated overnight compared to those being extubated at daytime [24].

\section{The problem of hyperox(em)ia}

Exposure to pure $\mathrm{O}_{2}$ for longer periods provokes pulmonary inflammation (hyperoxic acute lung injury, HALI, or " $\mathrm{O}_{2}$-toxicity"), but in the absence of high-stretch mechanical ventilation, the risk of HALI is minimal when the $\mathrm{FiO}_{2}$ is $\leq 0.6$, and the risk probably begins when the $\mathrm{FiO}_{2}$ exceeds 0.7 for several hours ( $\geq 24 \mathrm{~h}$ ). However, resorption atelectasis, which increases right-to-left blood shunting and deteriorate pulmonary gas exchange, may appear within minutes after induction of anaesthesia and increase postoperative pulmonary complications [25]. Likewise, a high $\mathrm{FiO}_{2}$ might cause respiratory depression in situations where respiratory drive becomes oxygen dependent, such as in patients with COPD or in postoperative patients with atelectasis and residual pain medication.

Furthermore, hyperoxia (high $\mathrm{PaO}_{2}$ ) decreases cardiac output by decreasing heart rate and causing systemic vasoconstriction [26]. Furthermore, hyperoxia is a potent vasoconstrictor stimulus to the coronary circulation, functioning at the level of the microvascular resistance vessels. This is why the hyperoxia related to routine use of high-flow oxygen in uncomplicated myocardial infarction may result in a greater infarct size and possibly increase the risk of mortality [27]. Yet the use of supplemental oxygen is widespread in cardiac patients, exposing them to significant periods of potential detrimental hyperoxia without monitoring oxygen tension [28]. It is noteworthy in this context that a lower $\mathrm{FiO}_{2}$ had no worse outcomes during cardiac surgery when compared to the higher concentrations that are commonly used in this setting [29].

Finally, it has recently been shown in volunteers that normobaric hyperoxia decreased capillary perfusion and muscle oxygen consumption and increased microcirculatory perfusion heterogeneity [30]. Since such microcirculatory alterations are independently associated with worse patient outcomes [31], the use of hyperoxia as a therapeutic strategy may be deleterious. Last but not least a very recent study has shown in 480 ventilated ICU patients that a conservative oxygen treatment causing only small differences in $\mathrm{PaO}_{2}(87$ vs. $102 \mathrm{mmHg}$ ) might cause a significant mortality benefit (11 vs. 20\%) [32].

Despite these negative effects, unintended hyperoxia seems to be quite common in daily ICU practice. According to a large Dutch study including 5498 mechanically ventilated patients, hyperoxia $\left(\mathrm{PaO}_{2}>120 \mathrm{mmHg}\right)$ was found in $22 \%$ of the arterial blood gas samples, but the $\mathrm{FiO}_{2}$ was subsequently decreased in only $25 \%$ of these instances, implying that hyperoxia was accepted [33]. In fact, another study found that ICU patients spent most of their time (59\%) in hyperoxemia, and when this occurred at an $\mathrm{FiO}_{2}$ between 0.3 and 0.4 , no $\mathrm{FiO}_{2}$ adjustments were made in $88 \%$ of these episodes [34]. Liberal oxygenation 
is also common in the pediatric ICU [35], despite existing guidelines to the contrary.

When looking at the relation between oxygen therapy and outcome, a recent study involving 14,441 ICU patients showed that severe hyperoxia $\left(\mathrm{PaO}_{2}>200 \mathrm{mmHg}\right)$ was associated with higher mortality rates (odds ratio 1.35) and fewer ventilator-free days compared to both mild hyperoxia $\left(\mathrm{PaO}_{2} 120-200 \mathrm{mmHg}\right)$ and normoxia. However, the adjusted probability of in-hospital death showed its lowest values at $\mathrm{PaO}_{2}$ values between 120 and $160 \mathrm{mmHg}$ [36]. Similar results were obtained in a previous study observing more than 36,000 patients from 50 ICUs in the Netherlands that revealed a U-shaped relationship between mortality and arterial $\mathrm{PO}_{2}$, with a nadir at $\mathrm{PaO}_{2}$ values of 15-20 kPa (110-150 mmHg) [37]. Similar results have been reported recently in two major trials including more than 5000 and 6000 patients after resuscitation from cardiac arrest, respectively: mortality sharply increased both at $\mathrm{PaO}_{2}$ values $<9 \mathrm{kPa}(<67 \mathrm{mmHg})$ and $>30 \mathrm{kPa}$ (>225 mmHg) [38], and hyperoxia was independently associated with increased in-hospital mortality [39]. In addition, a recent meta-analysis of 16 studies covering more than 49,000 patients revealed a crude odds ratio of 1.38 (95\% CI $1.18-1.63)(p<0.0001)$ for in-hospital mortality when patients were hyperoxic, independent of admission diagnosis [40]. However, a review of 152,680 ventilated ICU patients demonstrated an association between hypoxia but not hyperoxia and increased in-hospital mortality during the first $24 \mathrm{~h} \mathrm{[21].}$

So according to the evidence it is quite clear that hyperoxemia in critically ill patients is not beneficial and may increase mortality and that the optimal $\mathrm{PaO}_{2}$ is not yet clearly defined. However, there may be situations where short periods of hyperoxia may actually increase patient safety, e.g. during the induction of anaesthesia and for intubation in ICU patients to delay the onset of hypoxemia during apnea [41, 42]. In fact, various maneuvers have been proposed to extend the effect of preoxygenation, including the use of high-flow nasal oxygen [43-45].

Finally, there is some experimental evidence on the potential benefit of hyperoxia during resuscitation from hemorrhagic shock [46] but not in septic shock [47].

\section{Monitoring oxygenation by pulse oximetry}

Arterial blood gas analysis (aBGA) is considered the gold standard of monitoring the oxygenation status. It does, however, require arterial blood sampling, which is intermittent, invasive, associated with blood loss, costly, and the results are often delayed. As a result, significant changes in oxygenation may go unnoticed in-between aBGA's when the arterial oxygen saturation $\left(\mathrm{SaO}_{2}\right)$ is close to $100 \%$ and therefore no longer informative (Fig. 1).

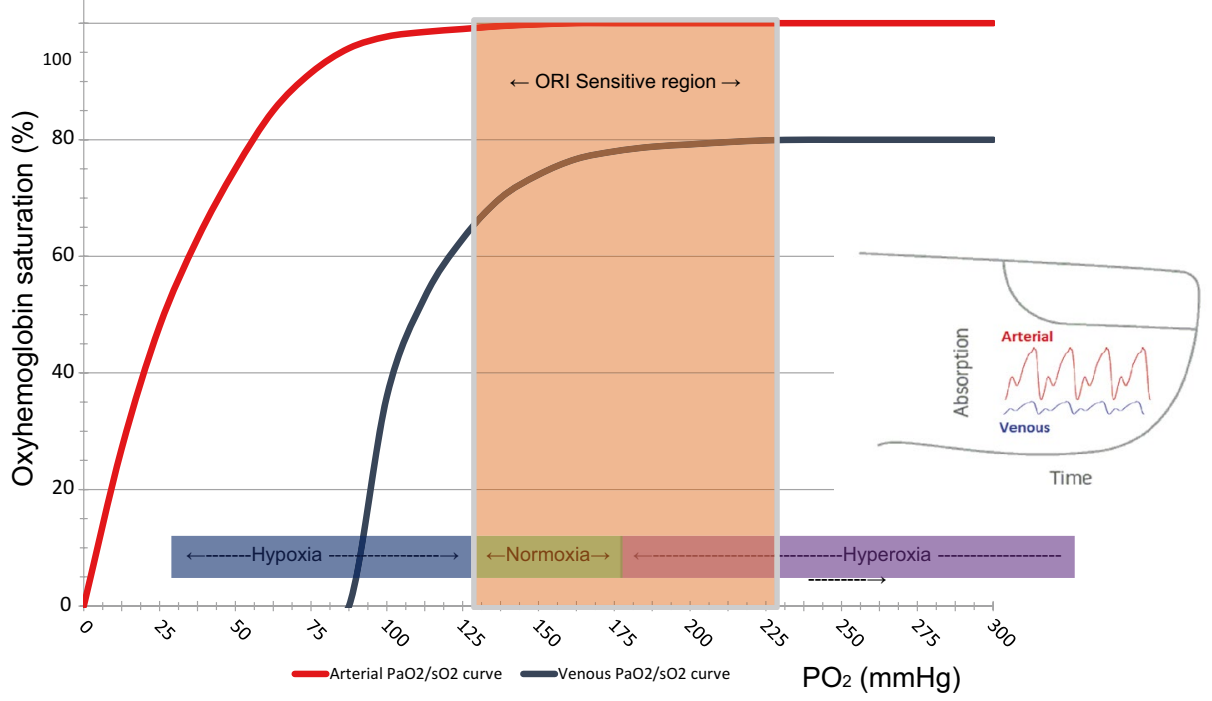

Fig. 1 Arterial (red line) and venous (blue line) oxyhaemoglobin dissociation curves. In the hypoxic rage $\left(\mathrm{PaO}_{2}<100 \mathrm{mmHg}\right)$, arterial oxygenation can be assessed by pulse oximetry $\left(\mathrm{SpO}_{2}\right)$. As $\mathrm{PaO}_{2}$ increases beyond $100 \mathrm{mmHg}$, venous saturation $\left(\mathrm{SvO}_{2}\right)$ at the measurement site increases even though arterial saturation $\left(\mathrm{SaO}_{2}\right)$ remains maximal and unchanged. This change in $\mathrm{SvO}_{2}$ causes changes in absorption of the incident light (and hence a change in measured signals) as $\mathrm{PaO}_{2}$ changes. With Masimo's Rainbow SET technology these signals are extractable and the system is able to detect changes in $\mathrm{PaO}_{2}$ through changes in $\mathrm{SvO}_{2}$ at the measurement site. $\mathrm{SvO}_{2}$ reaches a plateau beyond a certain level of $\mathrm{PaO}_{2}$, approximately $200 \mathrm{mmHg}$ (hyperoxic range), and consequently ORI is sensitive to the changes in $\mathrm{PaO}_{2}$ in the range between 100 and $200 \mathrm{mmHg}$ (orange shaded area) 
The most common method to monitor oxygenation is the non-invasive continuous pulse oximetry which has become a universal standard of care in anaesthesia, intensive care medicine, and other patient populations who are susceptible to become hypoxemic [3]. Pulse oximetry measures hemoglobin oxygen saturation $\left(\mathrm{SpO}_{2}\right)$ by light absorption typically at the finger or the earlobe. The accuracy of pulse oximetry as compared with invasive measurements is good with a bias between $\mathrm{SpO}_{2}$ and $\mathrm{SaO}_{2}<2 \%$ and a precision $<3 \%$ [3].

It is of interest to note that although the routine monitoring of $\mathrm{SpO}_{2}$ with pulse oximetry has become mandatory in anaesthesia and critical care, there is no formal evidencebase showing its positive impact on patient outcome [48].

Nevertheless, and in agreement with current strong conviction, the relative number of respiratory complications during anaesthesia and associated malpractice claims has dropped significantly and consistently since the introduction of pulse oximeters $[49,50]$.

Pulse oximetry has a major limitation when it comes to assessing or preventing hyperoxemia in patients that receive oxygen therapy. Due to the sigmoid shape of the oxyhemoglobin dissociation curve, $\mathrm{SpO}_{2}$ is near complete at a $\mathrm{PaO}_{2}$ of 90-100 $\mathrm{mmHg}$, and increasing the $\mathrm{PaO}_{2}$ above this level will no longer affect the $\mathrm{SpO}_{2}$. As a consequence, when $\mathrm{SpO}_{2}$ is $\geq 97 \%$, the $\mathrm{PaO}_{2}$ level could be anywhere between 90 and $600 \mathrm{mmHg}$. Hence, only a direct measurement of the $\mathrm{PaO}_{2}$, as part of aBGA, can be used to assess the hyperoxic range. Another way to assess oxygenation status in the hyperoxic range is by gradually decreasing the inspired oxygen concentration $\left(\mathrm{FiO}_{2}\right)$ until $\mathrm{SpO}_{2}$ starts to decrease, as recently suggested [51]. This maneuver, however, takes several minutes and may culminate in undesirable low $\mathrm{SpO}_{2}$ levels, making the procedure impractical in cases where the clinical situation does not allow to decrease the $\mathrm{FiO}_{2}$. As a result of these limitations, the monitoring of $\mathrm{SpO}_{2}$ alone cannot identify clinically important changes that may occur in the oxygenation status in the hyperoxic range, nor can it rule out the presence of unintended hyperoxia in patients receiving oxygen therapy.

Finally, pulse oximetry alone is a late detector of respiratory depression even when associated with considerable $\mathrm{CO}_{2}$ retention if supplemental oxygen is being administered [52].

\section{New development: the oxygen reserve index (ORI)}

The oxygen reserve index (ORI) is a new development in multiple wavelength pulse oximetry that reflects, in real-time and non-invasively, the oxygenation status in the moderate hyperoxic range $\left(\mathrm{PaO}_{2}\right.$ of approximately $100-200 \mathrm{mmHg}$, see shaded area in Fig. 1) in patients receiving supplemental oxygen. The measurement of this new variable has been made possible by the ability of multiwave length pulse cooximetry (Rainbow SET, Masimo Inc., Irvine, Ca., USA) to analyse both arterial and venous pulsatile blood absorption changes of incident light in a finger. When oxygen is being administered, the $\mathrm{PaO}_{2}$ increases to $>100 \mathrm{mmHg}$ and the $\mathrm{SpO}_{2}$ maximizes at close to $100 \%$. However, the venous oxygen saturation $\left(\mathrm{SvO}_{2}\right)$ at the measurement site continues to increase until it stabilizes (at about $80 \%$ saturation) when the $\mathrm{PaO}_{2}$ reaches about $200 \mathrm{mmHg}$ (Fig. 1). By combining the Fick and oxygen content equations, the resulting change in light absorption over this $\mathrm{PaO}_{2}$ range is the basis for the ORI calculation. Hence, the ORI is an index with a unit-less scale between 0.00 and 1.00 , which is a relative indicator of changes in $\mathrm{PaO}_{2}$ in the moderate hyperoxic range (approximately $100-200 \mathrm{mmHg}$ ), and is aimed for use in patients receiving supplemental oxygen [53]. It has to be stressed that ORI is not equivalent to $\mathrm{PaO}_{2}$ and cannot replace arterial blood gas analysis and/or 'classic' pulse oximetry. For further information about the principles of measurement and calculation of the ORI the interested reader is referred to reference [53] and the appendix of reference [54].

\section{Preliminary results from the perioperative setting}

There are two clinical studies published as of yet demonstrating that the ORI may provide an early warning when arterial oxygenation deteriorates before any changes in $\mathrm{SpO}_{2}$ occur. In the first study, Szmuk et al. followed the ORI during induction of anaesthesia in 25 healthy children [54]. They found that ORI detected an impeding desaturation in median of $31.5 \mathrm{~s}$ (range 19-34.3 s) before changes in $\mathrm{SpO}_{2}$ occurred and concluded that this represents a clinically important warning time, which might give clinicians time for corrective actions. This statement has been emphasized by the accompanying editorial, acknowledging a promising role of ORI for patient safety [55]. The second study looked at the relationship between ORI and $\mathrm{PaO}_{2}$ in 106 patients undergoing surgery and found a significant positive relationship for both absolute values $\left(r^{2}=0.536\right)$ and changes of both variables $\left(r^{2}=0.421\right)$ in the $\mathrm{PaO}_{2}$ range up to $240 \mathrm{mmHg}$ [56].

As illustrated in a plot obtained from an individual patient undergoing surgery (Fig. 2), the ORI (black line) indicated a decrease in oxygenation $30 \mathrm{~min}$ before the next aBGA (red diamond) revealed that the $\mathrm{PaO}_{2}$ had in the meantime decreased from 500 to $100 \mathrm{mmHg}$ while the $\mathrm{SpO}_{2}$ (green line) remained unchanged [56].

Recently, we performed a validation study of ORI in healthy volunteers, preliminary results of which have been presented at the Euroanaesthesia 2016 meeting in London 
Fig. 2 Example of continuous intraoperative oxygen reserve index trend (ORI; black line), continuous pulse oxygen saturation trend $\left(\mathrm{SpO}_{2}\right.$; green line $)$, and intermittent arterial partial pressure of oxygen determination $\left(\mathrm{PaO}_{2} ;\right.$ red diamonds $)$ obtained during surgery. ORI decreased during $30 \mathrm{~min}$ before aBGA documented a large decrease in $\mathrm{PaO}_{2}$. Reprinted with permission from [56]

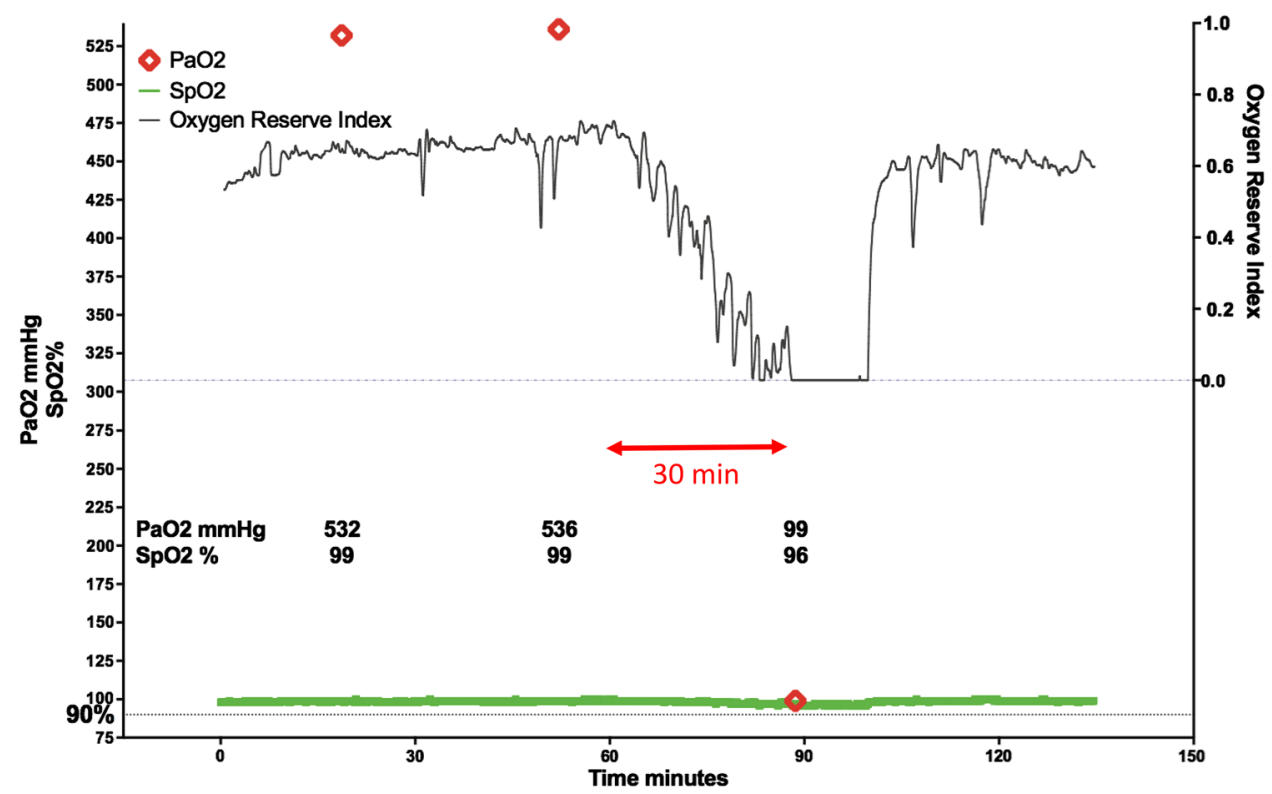

[57]. Volunteers were breathing via a tight fitting facemask standardized oxygen concentrations in a stepwise fashion, ranging from ambient air $\left(\mathrm{FiO}_{2} 0.21\right)$ to pure oxygen $\left(\mathrm{FiO}_{2}\right.$ $1.0)$, followed by a short period of mild hypoxia $\left(\mathrm{FiO}_{2} 0.14\right)$. As shown in the representative example (Fig. 3), the ORI followed closely the changes in $\mathrm{PaO}_{2}$ related to changes in $\mathrm{FiO}_{2}$, peaking at values of 0.55 and 0.60 respectively with maximum $\mathrm{FiO}_{2}$. A later gradual decrease in $\mathrm{FiO}_{2}$ led to a decrease in ORI values, which reached zero just before the
$\mathrm{SpO}_{2}$ (green line) started to decrease following the breathing of the hypoxic $\mathrm{FiO}_{2}$. Our results clearly show that the ORI reflects changes in oxygenation due to changes in $\mathrm{FiO}_{2}$, and that a decline in ORI following a decrease in $\mathrm{FiO}_{2}$ occurs well before any changes in $\mathrm{SpO}_{2}$ occur. It is important to note that in a recently revised version of the disposable pulse oximeter sensor (code $\mathrm{M}$ rainbow R1), the ORI has been rescaled so that it will reach the maximum value of 1.0 in more patients.

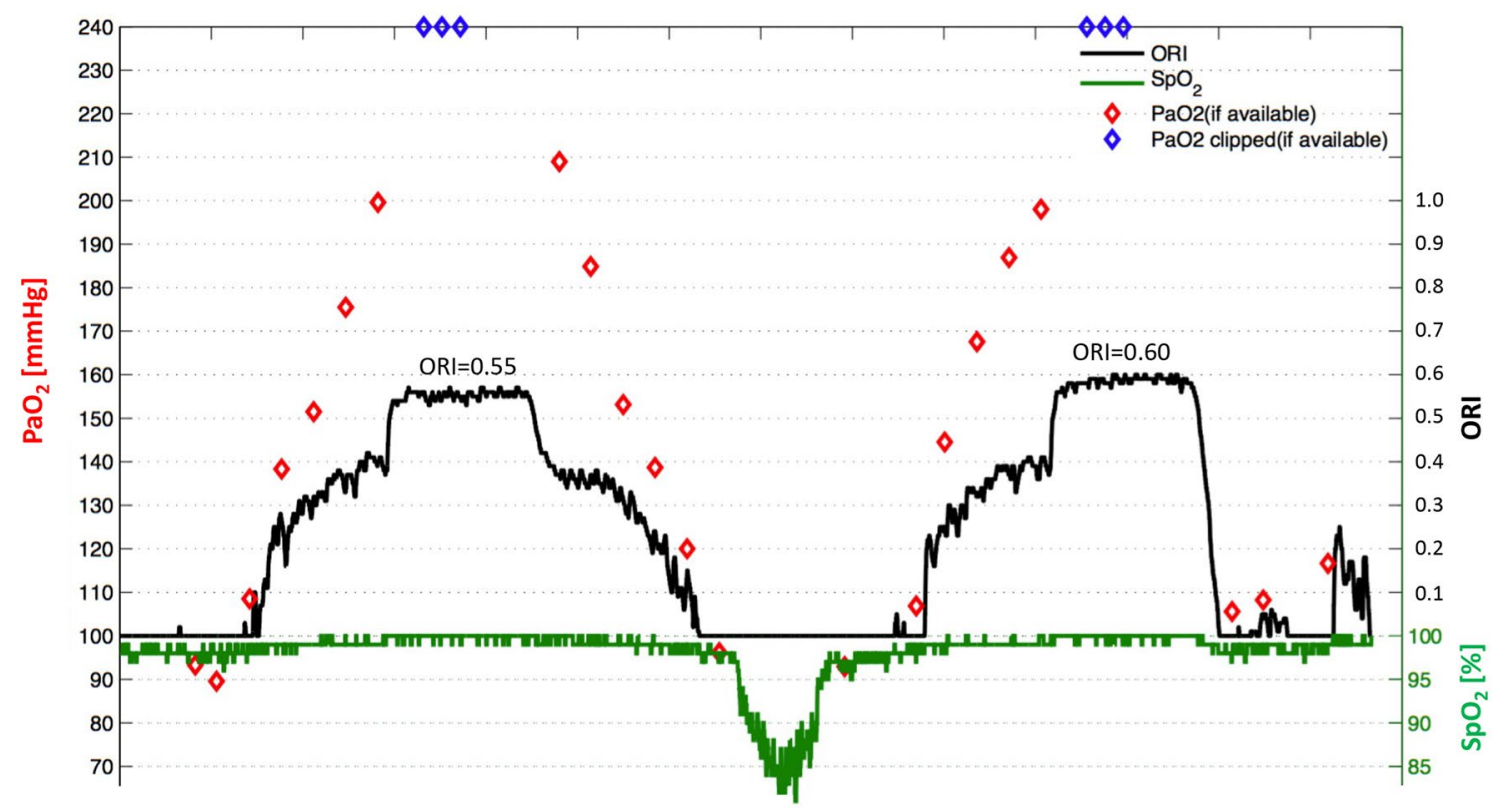

Fig. 3 Representative example from a volunteer breathing via a tight-fitting facemask standardized oxygen concentrations ranging from normoxia $\left(\mathrm{FiO}_{2} 0.21\right)$ to hyperoxia $\left(\mathrm{FiO}_{2} 1.0\right)$ and mild hypoxia $\left(\mathrm{FiO}_{2} 0.14\right)$ in a stepwise fashion 


\section{The potential clinical utility of the ORI}

\subsection{Response to oxygen administration and to preoxygenation}

Since the ORI has been introduced into clinical practice only recently, we will provide a theoretical exploration of its possible clinical utility in patients who receive supplemental oxygen. First of all, the ORI may provide information regarding the patient's initial response to acute oxygen therapy [58]. This information may be of great importance, since the persistence of a low ORI in spite of a high $\mathrm{FiO}_{2}$ may reflect the presence of high intrapulmonary shunting, ventilation/perfusion mismatch or hypoventilation. The most common example of V/Q mismatch is atelectasis related to induction of anaesthesia. A major cause of anaesthesia-induced lung collapse in this period is the use of high inspired oxygen concentration. Loss of muscle tone and muscle paralysis, compression of lung tissue due to heart weight and loss of surfactant function reduces functional residual capacity, producing gas trapping and resorption atelectasis behind closed airways. All these mechanisms are well reviewed elsewhere [59-61].

The ORI may also prove useful during the pre-oxygenation that is routinely done before endotracheal intubation and extubation and whenever there is an anticipated interruption in oxygen delivery (Fig. 4). The importance of performing preoxygenation correctly has been recently described again [42, 44, 62].

By increasing pulmonary oxygen reserve, well-performed preoxygenation may extend the 'tolerable apnea time', defined as the time until the $\mathrm{SpO}_{2}$ reaches $90 \%$, to almost $10 \mathrm{~min}$ [62], and hence make endotracheal intubation safer. In patients with normal pulmonary function, a well-performed preoxygenation can be easily tracked by the response of the ORI (Fig. 4). However, in obese patients and in the critically ill, preoxygenation by breathing $100 \% \mathrm{O}_{2}$ alone may not achieve the expected increase in oxygen reserve, and further interventions like positive-pressure ventilation and CPAP may be necessary $[62,63]$. The ORI may therefore be useful in identifying those patients who do not increase their oxygenation in response to preoxygenation, as reliance on the $\mathrm{SpO}_{2}$ only may be misleading in such cases [63]. Monitoring of ORI may also help in identifying a faulty preoxygenation technique, including a low or absent fresh oxygen flow, presence of gas-leaks due to an ill-fitting mask, shallow breathing, too short pre-oxygenation period, etc.

\subsection{Better titration of $\mathrm{FiO}_{2}$}

The ORI may be a useful tool for the correct titration of the $\mathrm{FiO}_{2}$. Although in the critically ill, ventilated patients pulse oximetry may be useful in maintaining patients above the hypoxemic levels by adjusting inspired oxygen fractions and ventilator settings [51], the $\mathrm{SpO}_{2}$ per se may not exclude the

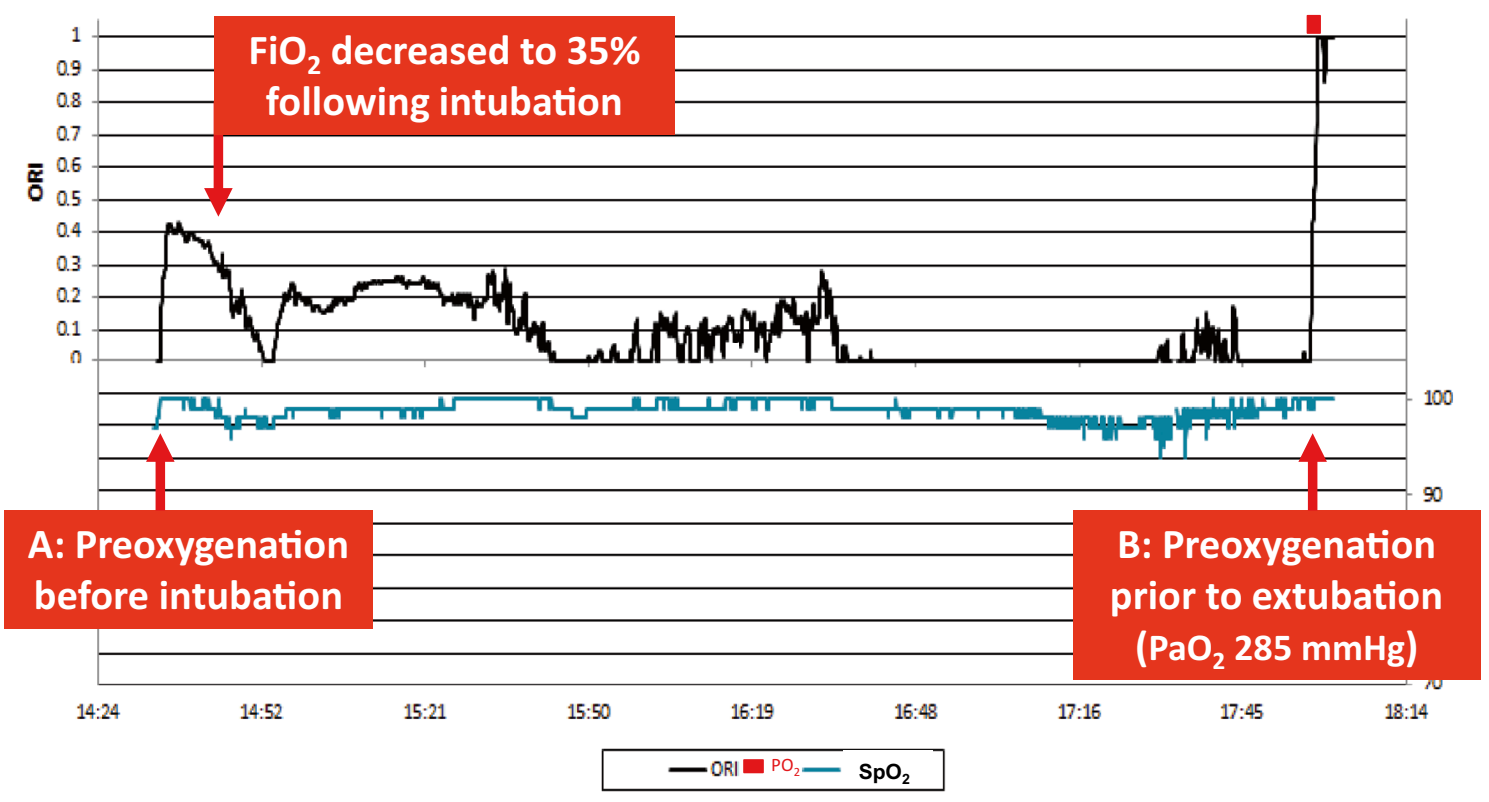

Fig. 4 Clinical graphic example of the ORI response in a patient receiving supplemental oxygen before tracheal intubation (pre-oxygenation) $(A)$ and again prior to extubation $(B)$. In both instances, the ORI sharply increases, making the effects of pre-oxygenation visible.
Following intubation, the $\mathrm{FiO}_{2}$ is reduced and titrated so that the ORI remained slightly above zero, indicating sufficient oxygenation of the arterial blood and avoiding hyperoxia at the same time. With kind permission from Drammen Sykehus, Norway 
presence of unintended hyperoxia without further time-consuming manipulations of the $\mathrm{FiO}_{2}$ or measuring aBGA. As stated before, unintended hyperoxia occurs very frequently in both adult and pediatric ICU patients [33-35].

\subsection{Early warning of impending hypoxemia}

The recent Prospective Evaluation of a RIsk Score for Postoperative Pulmonary COmPlications in Europe (PERISCOPE) study showed that about $4.2 \%$ of surgical patients develop postoperative respiratory failure, carrying an in-hospital mortality of $10.3 \%$ (vs. $0.4 \%$ in the rest of the patients), and defined risk factors for development of postoperative respiratory failure [64]. Such susceptible high-risk surgical patients, including those who undergo bariatric surgery [65], may benefit from earlier detection of postoperative respiratory failure. These patients often receive oxygen therapy which, as said before, renders routine pulse oximetry to be an inadequate tool for an early detection of developing hypoxemia and/or hypoventilation, so that postoperative monitoring with ORI should be considered.

The ORI might also be used to monitor oxygenation during high-flow nasal cannula oxygenation, used in patients who are not or no longer intubated and mechanically ventilated, in obese patients or during bronchoscopy [66]. Particularly the increasing number of obese patients admitted to the ICU postoperatively or requiring long-term non-invasive ventilation (NIV) might be a future indication for ORI monitoring in order to prevent respiratory failure [67] or unintended hyperoxia.

Several recently published trials would have benefitted from the use of ORI if it had been available, such as two RCTs of apneic oxygenation during endotracheal intubation of the critically ill $[68,69]$, the CLOSE study comparing conservative versus a liberal oxygenation targets for mechanical ventilation [70], or the OPERA trial looking at the effects of high-flow nasal cannula oxygen therapy to prevent hyperoxia after major abdominal surgery [71].

\subsection{Immediate response to changes in PEEP and to recruitment manoeuvres}

The ORI may reflect the immediate response of the $\mathrm{PaO}_{2}$ to therapeutic measures like adjusting positive end-expiratory pressure (PEEP) and recruitment manoeuvres. In a recent pilot study we have examined the effects of recruiting maneuvers on the ORI in ICU patients [72]. As can be seen in Fig. 5, the incremental increase in airway pressure during the maneuver is closely followed by an increase in the ORI. During the decremental PEEP trial (for finding the optimal PEEP) the ORI maintains a high value until the closing point appears where a sharp decrease in ORI is observed. This example demonstrates that the ORI may be a useful

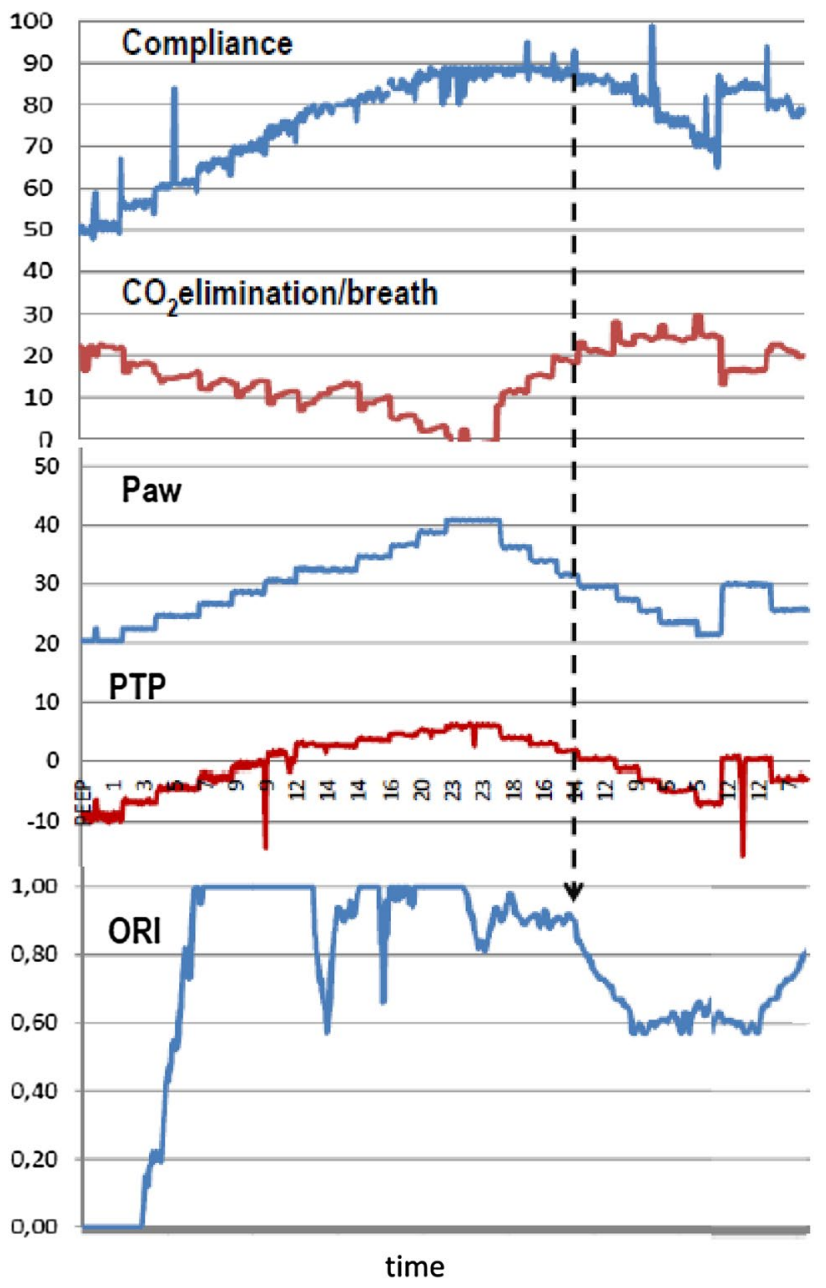

Fig. 5 Representative example of simultaneous trends in Compliance $\left(\mathrm{ml} / \mathrm{cmH}_{2} \mathrm{O}\right), \mathrm{CO}_{2}$ elimination per breath $(\mathrm{ml})$, airway pressure (Paw, $\left.\mathrm{cmH}_{2} \mathrm{O}\right)$, transpulmonary pressure $\left(\mathrm{PTP}, \mathrm{cmH}_{2} \mathrm{O}\right)$ and ORI values of a patient during a recruiting maneuver $(\mathrm{RM})$. While Paw rises in steps at the beginning of the RM, PTP and compliance rise accordingly and ORI increases up to a maximum value. Increases of dead space due to distention reduces the $\mathrm{CO}_{2}$ elimination per breath. During the decremental PEEP trial, step-reductions in Paw and PTP do not reduce compliance or ORI values until a closing point is observed. The dotted arrow shows this point in which an abrupt drop in compliance and ORI coincide with a negative value of TPT indicating re-collapse of the lung. The optimal PEEP corresponds to the previous setting

non-invasive tool for following oxygenation at any $\mathrm{FiO}_{2}$ during recruiting maneuvers and determining the optimal PEEP for an individualized lung-protective strategy in ICU patients.

\subsection{Possible limitations of the ORI}

Although the ORI may reflect oxygenation in the moderate hyperoxic range, it should not be considered as equivalent to $\mathrm{PaO}_{2}$ and is certainly not meant to replace pulse oximetry $\left(\mathrm{SpO}_{2}\right)$. The ORI should be considered as complementing 


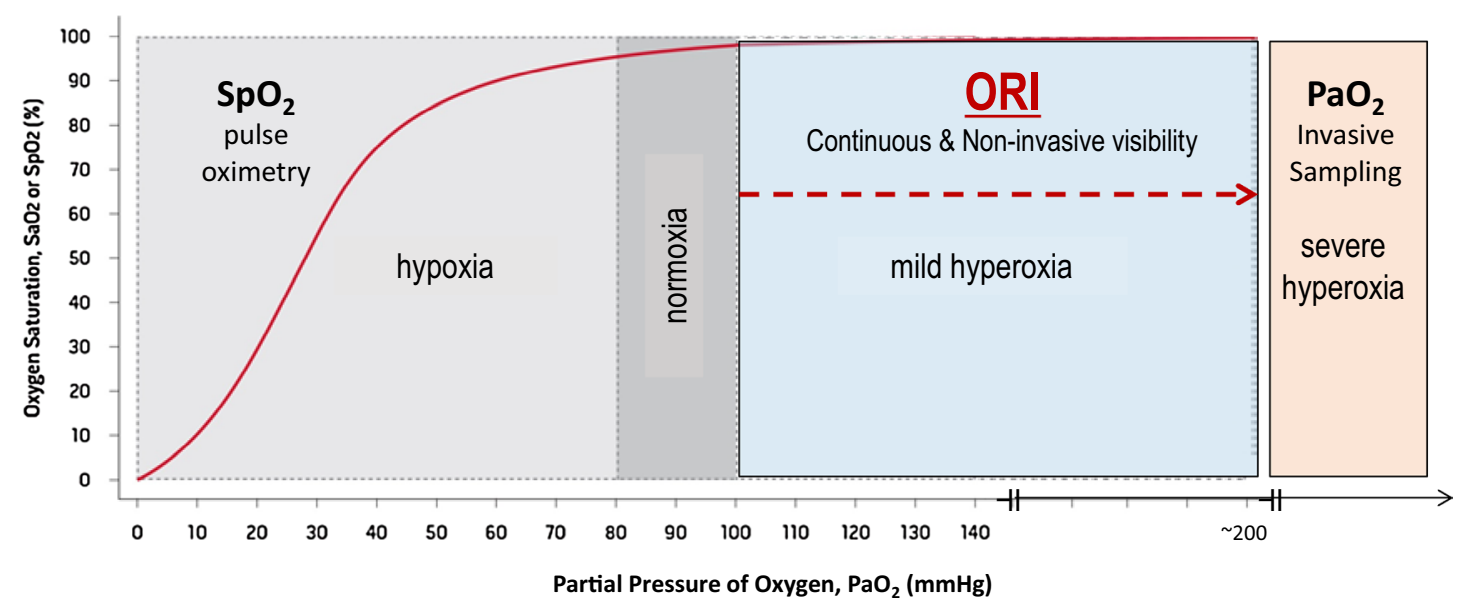

Fig. 6 Oxyhaemoglobin dissociation curve showing the potential usefulness of the continuous and non-invasive oxygen reserve index (ORI). The ORI has its place in the mild hyperoxic range $\left(\mathrm{PaO}_{2} 100\right.$

$\mathrm{SpO}_{2}$ for monitoring the oxygen status in patients receiving supplemental oxygen. Since the ORI measurement and calculation are affected by a variety of factors (e.g., pH, temp, $\mathrm{PaCO}_{2}$, etc.) it has a significant inter-individual variability. In addition, most individuals will not reach an ORI above 0.6-0.7 (at least with the first version of the ORI sensor) when breathing at an $\mathrm{FiO}_{2}$ close to 1.0, so that an individualized scaling of the maximum ORI being reached while breathing pure oxygen might be useful. Finally, like pulse oximetry $\left(\mathrm{SpO}_{2}\right)$, the ORI may not read when peripheral perfusion (at the finger) is impaired, such as in shock states or during high-dose vasopressor therapy.

\subsection{ORI summary}

Figure 6 summarizes the place that the ORI could take in monitoring the patient's oxygenation status, namely the mild hyperoxic rage $\left(\mathrm{PaO}_{2} 100-200 \mathrm{mmHg}\right)$. Below this range, pulse oximetry can easily be used to detect a decrease in $\mathrm{SpO}_{2}$. For higher $\mathrm{PaO}_{2}$ values, invasive arterial blood sampling and aBGA must be used.

\section{Conclusions}

The ORI is a new promising variable that serves as a relative indicator of the $\mathrm{PaO}_{2}$ in the range of $100-200 \mathrm{mmHg}$. Its addition to conventional pulse oximetry opens new opportunities in the continuous, non-invasive monitoring of the oxygenation status in patients receiving supplemental oxygen. The ORI may potentially allow better control of pre-oxygenation, provide an alarm of decreasing oxygenation well before any decrease in $\mathrm{SpO}_{2}$, allow a more adequate titration of oxygen
$200 \mathrm{mmHg}$ ). For lower values, pulse oximetry for monitoring $\mathrm{SaO}_{2}$ is useful, for higher values, invasive sampling and arterial blood gas analysis for measuring $\mathrm{PaO}_{2}$ must be used

therapy and prevent unintended hyperoxia, and reflect the immediate impact of recruitment maneuvers and PEEP adjustments. Further studies are needed to determine the potential role of the ORI in the management of acutely ill patients who are in need of oxygen supplementation.

\section{Compliance with ethical standards}

Conflict of interest TWLS received honoraria from and Masimo Inc. (Irvine, CA, USA) for consulting and lecturing. TWLS is an associate editor of the Journal of Clinical Monitoring and Computing, but had no role in the handling of this manuscript. FJB received honoraria from Philips, Pulsion and Masimo Inc. (Irvine, CA, USA) for lectures. AP serves as consultant for Masimo Inc. (Irvine, CA, USA) and received honoraria for lectures. AP is also a member of the medical advisory board of Pulsion/Getinge.

Informed consent Not applicable. This is a review article not including primary research on human participants and/or animals.

Research involving human participants and/or animals Not applicable. This is a review article not including human participants and/ or animals.

Open Access This article is distributed under the terms of the Creative Commons Attribution 4.0 International License (http://creativecommons.org/licenses/by/4.0/), which permits unrestricted use, distribution, and reproduction in any medium, provided you give appropriate credit to the original author(s) and the source, provide a link to the Creative Commons license, and indicate if changes were made.

\section{References}

1. Branson RD, Robinson BR. Oxygen: when is more the enemy of good? Intensive Care Med. 2011;37(1):1-3. doi:10.1007/ s00134-010-2034-y. 
2. Martin DS, Grocott MP. Oxygen therapy in anaesthesia: the yin and yang of O2. Br J Anaesth. 2013;111(6):867-71. doi:10.1093/bja/aet291.

3. Jubran A. Pulse oximetry. Crit Care. 2015;19:272. doi:10.1186/ s13054-015-0984-8.

4. Dyson A, Singer M. Tissue oxygen tension monitoring: will it fill the void? Curr Opin Crit Care. 2011;17(3):281-9. doi:10.1097/MCC.0b013e328344f1dc.

5. Ehrenfeld JM, Funk LM, Van Schalkwyk J, Merry AF, Sandberg WS, Gawande A. The incidence of hypoxemia during surgery: evidence from two institutions. Can J Anaesth. 2010;57(10):888-97. doi:10.1007/s12630-010-9366-5.

6. Drummond GB, Park GR. Arterial oxygen saturation before intubation of the trachea. An assessment of oxygenation techniques. Br J Anaesth. 1984;56(9):987-93.

7. Tait AR, Voepel-Lewis T, Burke C, Kostrzewa A, Lewis I. Incidence and risk factors for perioperative adverse respiratory events in children who are obese. Anesthesiology. 2008;108(3):375-80. doi:10.1097/ALN.0b013e318164ca9b.

8. Cook TM, MacDougall-Davis SR. Complications and failure of airway management. Br J Anaesth. 2012;109(Suppl 1):i68-i85. doi:10.1093/bja/aes393.

9. Gebremedhn EG, Mesele D, Aemero D, Alemu E. The incidence of oxygen desaturation during rapid sequence induction and intubation. World J Emerg Med. 2014;5(4):279-85. doi:10.5847/wjem.j.issn.1920-8642.2014.04.007.

10. $\mathrm{Ng} \mathrm{A}$, Swanevelder J. Hypoxaemia associated with one-lung anaesthesia: new discoveries in ventilation and perfusion. $\mathrm{Br} \mathrm{J}$ Anaesth. 2011;106(6):761-3. doi:10.1093/bja/aer113.

11. Cote CJ, Rolf N, Liu LM, Goudsouzian NG, Ryan JF, Zaslavsky A, Gore R, Todres TD, Vassallo S, Polaner D, et al. A singleblind study of combined pulse oximetry and capnography in children. Anesthesiology. 1991;74(6):980-7.

12. Sun Z, Sessler DI, Dalton JE, Devereaux PJ, Shahinyan A, Naylor AJ, Hutcherson MT, Finnegan PS, Tandon V, DarvishKazem S, Chugh S, Alzayer H, Kurz A. Postoperative hypoxemia is common and persistent: a prospective blinded observational study. Anesth Analg. 2015;121(3):709-15. doi:10.1213/ ANE.0000000000000836.

13. Epstein RH, Dexter F, Lopez MG, Ehrenfeld JM. Anesthesiologist staffing considerations consequent to the temporal distribution of hypoxemic episodes in the postanesthesia care unit. Anesth Analg. 2014;119(6):1322-33. doi:10.1213/ ANE.0000000000000410.

14. Weingarten TN, Warner LL, Sprung J. Timing of postoperative respiratory emergencies: when do they really occur? Curr Opin Anaesthesiol. 2017;30(1):156-62. doi:10.1097/ ACO.0000000000000401.

15. Sarton E, Romberg R, Nieuwenhuijs D, Teppema LJ, Vuyk J, Schraag S, Dahan A. The effect of anesthetics on control of respiration. Anaesthesist. 2002;51(4):285-91.

16. Gunnarsson L, Tokics L, Gustavsson H, Hedenstierna G. Influence of age on atelectasis formation and gas exchange impairment during general anaesthesia. Br J Anaesth. 1991;66(4):423-32.

17. Hewlett AM, Branthwaite MA. Postoperative pulmonary function. Br J Anaesth. 1975;47(2):102-7.

18. Canet J, Ricos M, Vidal F. Early postoperative arterial oxygen desaturation. Determining factors and response to oxygen therapy. Anesth Analg. 1989;69(2):207-12.

19. Moller JT, Wittrup M, Johansen SH. Hypoxemia in the postanesthesia care unit: an observer study. Anesthesiology. 1990;73(5):890-5.

20. Walker M, Farmer RG, Schelew B. Risk factors for oxygen desaturation on arrival in the postanesthesia care unit. Can J Anaesth. 2015;62(9):1019-20. doi:10.1007/s12630-015-0371-6.
21. Eastwood G, Bellomo R, Bailey M, Taori G, Pilcher D, Young $\mathrm{P}$, Beasley R. Arterial oxygen tension and mortality in mechanically ventilated patients. Intensive Care Med. 2012;38(1):91-8. doi:10.1007/s00134-011-2419-6.

22. Higgs A, Cook TM, McGrath BA. Airway management in the critically ill: the same, but different. Br J Anaesth. 2016;117(Suppl 1):i5-i9. doi:10.1093/bja/aew055.

23. Cook TM, Woodall N, Harper J, Benger J, Fourth National Audit Project. Major complications of airway management in the UK: results of the Fourth National Audit Project of the Royal College of Anaesthetists and the Difficult Airway Society. Part 2: intensive care and emergency departments. Br J Anaesth. 2011;106(5):63242. doi:10.1093/bja/aer059.

24. Gershengorn HB, Scales DC, Kramer A, Wunsch H. Association between overnight extubations and outcomes in the intensive care unit. JAMA Intern Med. 2016;176(11):1651-1660. doi:10.1001/ jamainternmed.2016.5258.

25. Duggan M, Kavanagh BP. Atelectasis in the perioperative patient. Curr Opin Anaesthesiol. 2007;20(1):37-42. doi:10.1097/ ACO.0b013e328011d7e5.

26. Asfar $P$, Singer M, Radermacher P. Understanding the benefits and harms of oxygen therapy. Intensive Care Med. 2015;41(6):111821. doi:10.1007/s00134-015-3670-z.

27. Wijesinghe M, Perrin K, Ranchord A, Simmonds M, Weatherall $\mathrm{M}$, Beasley R. Routine use of oxygen in the treatment of myocardial infarction: systematic review. Heart. 2009;95(3):198-202. doi:10.1136/hrt.2008.148742.

28. Moradkhan R, Sinoway LI. Revisiting the role of oxygen therapy in cardiac patients. J Am Coll Cardiol. 2010;56(13):1013-6. doi:10.1016/j.jacc.2010.04.052.

29. Smit B, Smulders YM, de Waard MC, Boer C, Vonk AB, Veerhoek D, Kamminga S, de Grooth HJ, Garcia-Vallejo JJ, Musters RJ, Girbes AR, Oudemans-van Straaten HM, Spoelstra-de Man AM. Moderate hyperoxic versus near-physiological oxygen targets during and after coronary artery bypass surgery: a randomised controlled trial. Crit Care. 2016;20:55. doi:10.1186/ s13054-016-1240-6.

30. Orbegozo Cortes D, Puflea F, Donadello K, Taccone FS, Gottin L, Creteur J, Vincent JL, De Backer D. Normobaric hyperoxia alters the microcirculation in healthy volunteers. Microvasc Res. 2015;98:23-8. doi:10.1016/j.mvr.2014.11.006.

31. Sakr Y, Dubois MJ, De Backer D, Creteur J, Vincent JL. Persistent microcirculatory alterations are associated with organ failure and death in patients with septic shock. Crit Care Med. 2004;32(9):1825-31.

32. Girardis M, Busani S, Damiani E, Donati A, Rinaldi L, Marudi A, Morelli A, Antonelli M, Singer M. Effect of conservative vs conventional oxygen therapy on mortality among patients in an intensive care unit: the oxygen-ICU randomized clinical trial. JAMA. 2016;316(15):1583-9. doi:10.1001/jama.2016.11993.

33. de Graaff AE, Dongelmans DA, Binnekade JM, de Jonge E. Clinicians' response to hyperoxia in ventilated patients in a Dutch ICU depends on the level of $\mathrm{FiO}_{2}$. Intensive Care Med. 2011;37(1):4651. doi:10.1007/s00134-010-2025-z.

34. Suzuki S, Eastwood GM, Peck L, Glassford NJ, Bellomo R. Current oxygen management in mechanically ventilated patients: a prospective observational cohort study. J Crit Care. 2013;28(5):647-54. doi:10.1016/j.jcrc.2013.03.010.

35. Ray S, Rogers L, Raman S, Peters MJ, Oxy Pi. Liberal oxygenation in paediatric intensive care: retrospective analysis of highresolution $\mathrm{SpO}_{2}$ data. Intensive Care Med. 2017;43(1):146-7. doi:10.1007/s00134-016-4606-y.

36. Helmerhorst HJ, Arts DL, Schultz MJ, van der Voort PH, AbuHanna A, de Jonge E, van Westerloo DJ. Metrics of arterial hyperoxia and associated outcomes in critical care. Crit Care Med. 2017;45(2):187-95. doi:10.1097/CCM.0000000000002084. 
37. de Jonge E, Peelen L, Keijzers PJ, Joore H, de Lange D, van der Voort PH, Bosman RJ, de Waal RA, Wesselink R, de Keizer NF. Association between administered oxygen, arterial partial oxygen pressure and mortality in mechanically ventilated intensive care unit patients. Crit Care. 2008;12(6):R156. doi:10.1186/cc7150.

38. Helmerhorst HJ, Roos-Blom MJ, van Westerloo DJ, Abu-Hanna A, de Keizer NF, de Jonge E. Associations of arterial carbon dioxide and arterial oxygen concentrations with hospital mortality after resuscitation from cardiac arrest. Crit Care. 2015;19:348. doi:10.1186/s13054-015-1067-6.

39. Kilgannon JH, Jones AE, Shapiro NI, Angelos MG, Milcarek B, Hunter K, Parrillo JE, Trzeciak S. Association between arterial hyperoxia following resuscitation from cardiac arrest and inhospital mortality. JAMA. 2010;303(21):2165-71. doi:10.1001/ jama.2010.707.

40. Helmerhorst HJ, Roos-Blom MJ, van Westerloo DJ, de Jonge E. Association between arterial hyperoxia and outcome in subsets of critical illness: a systematic review, metaanalysis, and metaregression of cohort studies. Crit Care Med. 2015;43(7):1508-19. doi:10.1097/CCM.0000000000000998.

41. Martin DS, Grocott MP. Oxygen therapy and anaesthesia: too much of a good thing? Anaesthesia. 2015;70(5):522-7. doi:10.1111/anae.13081.

42. Nimmagadda U, Salem MR, Crystal GJ. Preoxygenation: physiologic basis, benefits, and potential risks. Anesth Analg. 2017;124(2):507-17. doi:10.1213/ANE.0000000000001589.

43. Ang KS, Green A, Ramaswamy KK, Frerk C. Preoxygenation using the Optiflow system. Br J Anaesth. 2017;118(3):463-4. doi:10.1093/bja/aex016.

44. Ricard JD. Hazards of intubation in the ICU: role of nasal high flow oxygen therapy for preoxygenation and apneic oxygenation to prevent desaturation. Minerva Anestesiol. 2016;82(10):1098-106.

45. Slinger PD. Is there anything new about preoxygenation? Duh, Yeah! Anesth Analg. 2017;124(2):388-9. doi:10.1213/ ANE.0000000000001764.

46. Kurita T, Morita K, Sato S. The influence of hypovolemia and fluid resuscitation during hemorrhagic shock on apneic oxygen desaturation after preoxygenation in a swine model. Anesth Analg. 2015;121(6):1555-61. doi:10.1213/ANE.0000000000000979.

47. Asfar P, Schortgen F, Boisrame-Helms J, Charpentier J, Guerot E, Megarbane B, Grimaldi D, Grelon F, Anguel N, Lasocki S, HenryLagarrigue M, Gonzalez F, Legay F, Guitton C, Schenck M, Doise JM, Devaquet J, Van Der Linden T, Chatellier D, Rigaud JP, Dellamonica J, Tamion F, Meziani F, Mercat A, Dreyfuss D, Seegers V, Radermacher P, HYPER2S Investigators, REVA Research Network. Hyperoxia and hypertonic saline in patients with septic shock (HYPERS2S): a two-by-two factorial, multicentre, randomised, clinical trial. Lancet Respir Med. 2017;5(3):180-90. doi:10.1016/S2213-2600(17)30046-2.

48. Pedersen T, Nicholson A, Hovhannisyan K, Moller AM, Smith AF, Lewis SR. Pulse oximetry for perioperative monitoring. Cochrane Database Syst Rev. 2014;3:CD002013. doi:10.1002/14651858. CD002013.pub3.

49. Lee LA, Domino KB. The Closed Claims Project. Has it influenced anesthetic practice and outcome? Anesthesiol Clin North Am. 2002;20(3):485-501.

50. Lee LA, Caplan RA, Stephens LS, Posner KL, Terman GW, Voepel-Lewis T, Domino KB. Postoperative opioid-induced respiratory depression: a closed claims analysis. Anesthesiology. 2015;122(3):659-65. doi:10.1097/ALN.0000000000000564.

51. Tusman G, Bohm SH, Suarez-Sipmann F. Advanced uses of pulse oximetry for monitoring mechanically ventilated patients. Anesth Analg. 2017;124(1):62-71. doi:10.1213/ ANE.0000000000001283.

52. Fu ES, Downs JB, Schweiger JW, Miguel RV, Smith RA. Supplemental oxygen impairs detection of hypoventilation by pulse oximetry. Chest. 2004;126(5):1552-8. doi:10.1378/ chest.126.5.1552.

53. Oxygen Reserve Index (ORITM). http://www.masimo.co.uk/pdf/ ori/LAB8543A_Whitepaper_ORI_British.pdf.

54. Szmuk P, Steiner JW, Olomu PN, Ploski RP, Sessler DI, Ezri T Oxygen reserve index: a novel noninvasive measure of oxygen reserve-a pilot study. Anesthesiology. 2016;124(4):779-84. doi:10.1097/ALN.0000000000001009.

55. Simpao AF, Galvez JA. When seconds count, buy more time: the oxygen reserve index and its promising role in patient monitoring and safety. Anesthesiology. 2016;124(4):750-1. doi:10.1097/ ALN.0000000000001036.

56. Applegate RL 2nd, Dorotta IL, Wells B, Juma D, Applegate PM. The relationship between oxygen reserve index and arterial partial pressure of oxygen during surgery. Anesth Analg. 2016;123(3):626-33. doi:10.1213/ANE.0000000000001262.

57. Scheeren TW, Spanjersberg R, Struys MM. Oxygen reserve index (ORI): validation of a new variable. Eur J Anaesthesiol. 2016;33(Supplement 54):01AP04-09.

58. Bateman NT, Leach RM. ABC of oxygen. Acute oxygen therapy. BMJ. 1998;317(7161):798-801.

59. Duggan M, Kavanagh BP. Pulmonary atelectasis: a pathogenic perioperative entity. Anesthesiology. 2005;102(4):838-54.

60. Hedenstierna G, Edmark L. Mechanisms of atelectasis in the perioperative period. Best Pract Res Clin Anaesthesiol. 2010;24(2):157-69.

61. Hedenstierna G. Oxygen and anesthesia: what lung do we deliver to the post-operative ward? Acta Anaesthesiol Scand. 2012;56(6):675-85. doi:10.1111/j.1399-6576.2012.02689.x.

62. Bouroche G, Bourgain JL. Preoxygenation and general anesthesia: a review. Minerva Anestesiol. 2015;81(8):910-20.

63. Mosier JM, Hypes CD, Sakles JC. Understanding preoxygenation and apneic oxygenation during intubation in the critically ill. Intensive Care Med. 2017;43(2):226-8. doi:10.1007/ s00134-016-4426-0.

64. Canet J, Sabate S, Mazo V, Gallart L, de Abreu MG, Belda J, Langeron O, Hoeft A, Pelosi P, PERISCOPE Group. Development and validation of a score to predict postoperative respiratory failure in a multicentre European cohort: a prospective, observational study. Eur J Anaesthesiol. 2015;32(7):458-70. doi:10.1097/ EJA.0000000000000223.

65. Gallagher SF, Haines KL, Osterlund LG, Mullen M, Downs JB. Postoperative hypoxemia: common, undetected, and unsuspected after bariatric surgery. J Surg Res. 2010;159(2):622-6. doi:10.1016/j.jss.2009.09.003.

66. Papazian L, Corley A, Hess D, Fraser JF, Frat JP, Guitton C, Jaber S, Maggiore SM, Nava S, Rello J, Ricard JD, Stephan F, Trisolini $\mathrm{R}$, Azoulay E. Use of high-flow nasal cannula oxygenation in ICU adults: a narrative review. Intensive Care Med. 2016;42(9):133649. doi:10.1007/s00134-016-4277-8.

67. Pepin JL, Timsit JF, Tamisier R, Borel JC, Levy P, Jaber S. Prevention and care of respiratory failure in obese patients. Lancet Respir Med. 2016;4(5):407-18. doi:10.1016/S2213-2600(16)00054-0.

68. Semler MW, Janz DR, Lentz RJ, Matthews DT, Norman BC, Assad TR, Keriwala RD, Ferrell BA, Noto MJ, McKown AC, Kocurek EG, Warren MA, Huerta LE, Rice TW, FELLOW Investigators, Pragmatic Critical Care Research Group, Randomized trial of apneic oxygenation during endotracheal intubation of the critically ill. Am J Respir Crit Care Med. 2016;193(3):273-80. doi: $10.1164 / \mathrm{rccm} .201507-12940 C$.

69. Jaber S, Monnin M, Girard M, Conseil M, Cisse M, Carr J, Mahul M, Delay JM, Belafia F, Chanques G, Molinari N, De Jong A. Apnoeic oxygenation via high-flow nasal cannula oxygen combined with non-invasive ventilation preoxygenation for intubation in hypoxaemic patients in the intensive care unit: the single-centre, 
blinded, randomised controlled OPTINIV trial. Intensive Care Med. 2016;42(12):1877-87. doi:10.1007/s00134-016-4588-9.

70. Panwar R, Hardie M, Bellomo R, Barrot L, Eastwood GM, Young PJ, Capellier G, Harrigan PW, Bailey M, CLOSE Study Investigators, ANZICS Clinical Trials Group. Conservative versus liberal oxygenation targets for mechanically ventilated patients. A pilot multicenter randomized controlled trial. Am J Respir Crit Care Med. 2016;193(1):43-51. doi:10.1164/rccm.201505-10190C.

71. Futier E, Paugam-Burtz C, Godet T, Khoy-Ear L, Rozencwajg S, Delay JM, Verzilli D, Dupuis J, Chanques G, Bazin JE, Constantin JM, Pereira B, Jaber S, OPERA Study Investigators.
Effect of early postextubation high-flow nasal cannula vs conventional oxygen therapy on hypoxaemia in patients after major abdominal surgery: a French multicentre randomised controlled trial (OPERA). Intensive Care Med. 2016;42(12):1888-98. doi:10.1007/s00134-016-4594-y.

72. Serralta F, Puig J, Gutierrez A, Ferrando C, Belda FJ. Monitoring of alveolar recruitment maneuvers using the Oxygen Reserve Index in the prevention of atelectasis formation in postoperative patients undergoing major surgery. Pilot, observational study. Eur J Anaesthesiol. 2017;34(e-supplement 55):280. 